\title{
Bridging the Digital Divide in the Changing Times: Application of A5
}

\section{Solutions}

\section{Subhajit Panda}

Assistant Librarian, University Library, Chandigarh University, Mohali, Punjab

Email: subhajit.e9641@ cumail.in

\section{Rupak Chakravarty}

Professor, Department of Library and Information Science, Panjab University, Chandigarh

Email: rupak@pu.ac.in

\section{ABSTRACT}

Disasters, either natural and man-made, adversely affect humanity including human lives and, the knowledge creation, as a standard of the progress of civilization. The development of education of a country depends upon the present economics, academic structure, research facilities, health issues and involvement of government ministry. The outbreak of present pandemic Coronavirus (official designation COVID-19 or 2019-nCov) has a clear negative impact on academic and research activities. It creates a global threat and people keep themselves at home to maintain social distancing for reducing the outbreak of community transmission. This COVID-19 epidemic is neither the first and confidently nor the last epidemic that will pose a threat to the conventional education system. Both the effects of education i.e. direct and indirect effects are a subject risk to such pandemic and other disaster vulnerability. Instead, efforts should be made to find measures which can ensure the continuation of the education system for posterity. This requirement of an alternate way of learning proves us for the transformation of the learning process from conventional to digital. The primary requirement of this transformation is the availability of a sophisticated and multitasking platform for online learning, which conforms A5 solutions. This A5 implies the 5A's of access, i.e. Availability, Adequacy, Accessibility, Affordability and Appropriateness; which bridges the digital divide by ensuring the equal access of web for all. In this paper, the authors have discussed the tool FCC (Free Conference Call), after evaluation and comparison which can use by learners and educators as an alternative solution of the physical classroom. This is a dissemination or sharing platform and most versatile and comprehensive free web-conferencing solution which can be used by academic institutions and educators for online classes. In addition, this paper also go through the comparative study of FCC and other known web conferencing tools to clarify the judgement of its acceptance. 
Keywords: 5A's of Access, COVID-19, Digital Divide, Digital Learning, FreeConferenceCall (FCC), Web Conferencing

\section{Introduction:}

This COVID-19 epidemic is neither the first and confidently nor the last epidemic that will pose a threat to the conventional education system. Both direct and indirect effects of education are a subject risk to such pandemic and other disaster vulnerability. Instead, efforts should be made to find measures which can ensure the continuation of the education system for posterity. The virtual online classroom may be an alternate solution to this problem which offer many benefits. In addition to its flexibility, online classrooms are accessible, affordable and convenient for learners as well as educators. Online classes can be easily accessed through a computer or mobile device, making it especially flexible for users to use in an extreme situation when there is the loss of communication or shut down of school, college and universities or they belong far away from the institution. With a computer or smartphone and access to Wi-Fi, an educator can host and learners can join an online class using various online platforms either paid or free. Our present study discussed the tool FCC (Free Conference Call), after evaluation and comparison which can use by learners and educators as an alternative solution of the physical classroom. In FCC educators can host an online meeting anytime, anywhere with the availability of internet access at absolutely no cost, making this platform the best of its kind. This paper also goes through the FCC's comparative analysis with the other known web conferencing tools to explain its acceptance.

\section{Statement of the Problem:}

In view of these unprecedented time of COVID-19 Pandemic, the recent UGC circular (dated $1^{\text {st }}$ July 2020) issued to the Vice-Chancellors of all the Universities having Human Resource Development Centres (HRDCs) regarding "Conduct ofcourses/programmes in Online Mode" directs the universities that the allocation of schedules to the HRDCs shall be done only for online mode of delivery (University Grants Commission, 2020). The HRDCs have been advised to offer all the programs allocated to them for 2020-21 only in ONLINE mode following a Standard Operating Procedures (SOPs). In addition to the Online Courses, all the HRDCs shall also organize Capacity Building Short-term Training Programs for Teachers on Using ICT for Online Teaching Learning Process. As a pre-requisites for switching over to online mode, it has to be understood that online education as a viable tool for reaching a large number of participants. Such virtual learning systems should have visual appeal making online classes an inviting, pleasant place to be. Participants needs to be sensitized in advance through introductory lectures relating to MOOCS and online delivery mode related challenges in pedagogy for continued interest in these programme along with their solutions. Resource persons shall be able to present text, videos, or links to other sources downloadable by the participants. Engaging the learner participant in conversations and increasing collaboration through discussion with resource persons and peer-to-peer support anytime, anywhere (University Grants Commission, 2018). Commit to continuous improvement through pro-active pre-preparation and delivery during the transition period of Pandemic Crises. Managing a small class or any academic event having fewer gathering can be easily achieved by the popular applications like Zoom, Cisco-Webex, Google Meet, Skype, etc. But for any academic event involving large number of participants requires paid services which may not me possible for all the HEIs including colleges and universities. In 
these context features of Free Conference Call (FCC) have been evaluated as a viable solution alongwith its comparision with other commercial platforms.

\section{The Literature Review:}

Learning is more effective, interactive, broad, not time-bound and not patterned only in the classroom (Grabowski et al., 2020). For understanding the increasing use of ICT in the world of education and its benefits to improve the quality of its outcomes, here we discussed some prominent literature which visualizes the use of ICT tools and technologies in the present situation of the pandemic COVID-19.

González-Sanmamed et al. (2020) deals with the revealing and analysis of the experience of the teachers' use of digital tools in their professional activities in the European country. While, Alolod et al. (2020) discussed the growing use of ICT by teachers for work tasks outside the formal working hours and premises, i.e. basically examine how technology acceptance relates to work-related ICT use after hours (WIA) and work-life balance and the use of digital learning environments (DLE) beyond school grounds and school hours. Ansong-Gyimah (2020) in his paper analyzes securitization theory and 25 declarations of emergency eLearning in the present condition of COVID-19 pandemic and the closure of universities and colleges at American universities. Murphy (2020) presents an exploration focused on the symbiotic connection between Informatics and eLearning that leads to contemporary and innovative solutions, facilitating and automating a wide variety of activities at information processing. Anthonysamy et al. (2020) promote a special type of software called Algodoo that present three types of activity that have observed during students' free exploration, which allows students to explore a range of physics phenomena within the same digital learning environment. And in another study, Blake et al. (2020) promote the most popular eLearning educational platform, Moodle-LMS (collaborative platform of Google and Microsoft) in Romanian universities, which contain mail group modules, virtual classes, video conferencing, presentation and testing. Muniasamy \& Alasiry (2020) studied the adaptation of Google Classroom as a very popular e-learning system by many African universities. With the use of seven experts from purposive sampling, Bauwens et al. (2020) examine how to synthesize the conceptual framework, develop a model and evaluate the model of a digital learning ecosystem. After examining cognitive engagement and metacognitive knowledge strategies on learning performance among Malaysian IT Undergraduates, Cotwright et al. (2020) described how cognitive learning processes influence the way students engage and learn online needs further investigation. Ivanova (2020) also focused on eye movement technology for evaluating and improving behaviours on digital learning content. While Mahmood et al. (2020) depict the current condition of digital culture in Indonesian education by pointing at the issue of students' digital fluency, particularly the readiness for using digital learning resources and smartphone usage. Gegenfurtner et al. (2020) introduced the discipline of Ethics and Academic Integrity (EAI) in the context of a great diversity of information sources in the application of the methods of antiplagiarism verification to the distance teaching through the eLearning platform. Hill \& Johnson (2020) discussed the reactions of training participants toward digital webinar-based training programs and the requirement of web conferencing and virtual classroom programs for effective digital education. In the context of Gaming and interactive evaluation in media management learning environments (PIGE-On), Kurdi et al. (2020) evaluate the flipped classroom (FC), a pedagogical model that transfers the work of certain learning processes outside the classroom. And the study of Mishra et al. (2020) analyses the extent to which university faculty use the technological resources that make up their Learning Ecologies to promote their professional development as educators. Kummanee et al. (2020) deal with a case study in which a digital 
learning object (DLO) was developed to assist in the pedagogical practice in higher education; as well as great concepts received in evaluations that refer to relevance, differentiation, credibility, and intention to use.

\section{Study Rationale:}

While after the start of the Covid-19 pandemic, there has been a flood of webinars, there are institutions willing to organize such events, but could not do so due to paucity of funds. Especially the educational institutions in developing and least developed countries were worst affected. Apart from the issues related to the stable, reliable and cost-effective Internet infrastructure, they are struggling with the platform for organizing such academic events for large user community including students and citizens. No such study has been conducted to test, evaluate, compare, analyse and recommend the most affordable platform for helping institutions and organization with inadequate financial resources for acquiring such web-conferencing platform/software.

\section{Scope of the Study:}

The study discusses the features of the web-conferencing tool FCC vis-a-vis other paid tools in the light of the 5A's of access, i.e. Availability, Adequacy, Accessibility, Affordability and Appropriateness. The other tools used for comparison include GotoMeeting (GTM), Zoom and Join.me. Wherever possible step-by-step procedure of using FCC for hosting live events like online class, virtual meetings, etc. and other features have been provided.

\section{Objectives:}

The study objectives includes:

i. To evaluate the features of FCC including Hosting, Screen share, Video conference, Chat, Screen Recording, Broadcaster and Integrations

ii. To illustrate the features of Desktop App, Web App and Mobile App.

iii. To compare the features of FCC with other proprietary solution like Zoom. GTM and Join.me.

\section{Methodology:}

The market is overloaded with different web-conferencing tools, all of which have a price tag not aligning with the purchasing power of low-budget small organizations. In order to identify the a versatile, comprehensive and pocket-friendly e-leaning/webinar/online -meeting solution, user accounts were created in several video-conferencing platforms including Zoom, GoToMeeting (GTM), Join.me, FCC, etc. Desktop app as well as mobile apps were installed. Testing and evaluation was done for each shortlisted platform on all the version, i.e., web, desktop as-well-as m-app. Feature comparisons were made considering the subscription cost. To identify the most affordable and multi-functional tool, comparative tables were made. Selection criteria used include maximum number of concurrent participants that could be accommodated simultaneously, maximum duration for which the online session could be extended, security features, ease of hosting and use, reporting, etc. 


\section{FCC Features:}

FCC is a website founded in 2001 in Long Beach, California. The company is one of the largest providers of conference call services online. It allow organizers (institutions/individuals) to host virtual meetings. FCC provides the feature of hosting (FreeConferenceCall, n.d.-c) any virtual event online through web-conferencing, screen sharing to share any type of content with the help of webcam. It also provides a free "Desktop App" for installation on the PC/Laptop. The desktop app also opens when the host login and select "Online Meetings" leading to the Meeting Wall. During the COVID crisis, we are offering all our users full access to our features for free including Online meetings and International calls for a limited time. The procedure to host a virtual event with the desktop app includes scheduling of the event: date and time, dial-in number, access code, online meeting link and online meeting ID. After scheduling, host can launch FCC desktop app and log in. Once the host the logged-in, all the online meeting features (FreeConferenceCall, n.d.-a) can be put to use as discussed below.

\begin{tabular}{|c|c|}
\hline Screen sharing & $\begin{array}{l}\text { 1. Access the Meeting Dashboard => Play } \\
\text { 2. Choose content to be shared and Start Sharing. }\end{array}$ \\
\hline Video conference & $\begin{array}{l}\text { 1. Meeting Dashboard }=>\text { Camera } \\
\text { 2. Use VoIP (Voice over Internet Protocol) }\end{array}$ \\
\hline Chat & $\begin{array}{l}\text { 1. Meeting Dashboard }=>\text { Chat } \\
\text { 2. Host can send messages to the group or private message to any specific } \\
\text { participant. }\end{array}$ \\
\hline Screen Recording & $\begin{array}{l}\text { FCC allows to record a screen sharing and/or video session during your meeting by } \\
\text { using Screen Recording. } \\
\text { 1. Content ((audio, screen sharing, video) recording can be done using the desktop } \\
\text { app or using the record feature available in the Meeting Dashboard. Recording can } \\
\text { also be used to create a Studio presentation. In case of video, only one video feed } \\
\text { will be recorded based on the active speaker. } \\
\text { 2. Previous recordings can be accessed through the "History \& Recordings" } \\
\text { available in the Meeting Wall. } \\
\text { 3. Recording feature is also available in any iOS device. }\end{array}$ \\
\hline Broadcaster & $\begin{array}{l}\text { 1. Previously recorded content can be streamed using the Broadcaster. It can be used } \\
\text { to upload HD A/V material including screen sharing files during a live session. } \\
\text { 2. There is no need to separate programme to download in order to broadcast } \\
\text { recordings as the Broadcaster is embedded on the Meeting Wall. } \\
\text { 3. Host can view the broadcast of their recorded sessions by accessing their Meeting } \\
\text { Wall => Broadcaster tab. }\end{array}$ \\
\hline Web Viewer & $\begin{array}{l}\text { Web Viewer allows participants to join online meetings with their web browsers } \\
\text { without the need to download and install the FCC desktop client. }\end{array}$ \\
\hline Integrations & $\begin{array}{l}\text { Every FCC account has following built-in integrations for MS Outlook and Google } \\
\text { Calendar Plug-ins/Extensions apart from several other. }\end{array}$ \\
\hline
\end{tabular}




\begin{tabular}{|l|ll|}
\hline System Requirements & 1. & OS: FCC supports Mac, Windows, and Ubuntu, Linux, iOS and Android \\
& 2. & Bandwidth: $100 \mathrm{~Kb} / \mathrm{s}(\mathrm{HD}$ Audio), $400 \mathrm{~Kb} / \mathrm{s}$ (screen sharing), $1.1 \mathrm{Mb} / \mathrm{s}$ (video) \\
& 3. & Desktop: Chrome ${ }^{\mathrm{TM}}$ 57, Firefox ${ }^{\circledR}$ 60, Safari ${ }^{\circledR} 10.1$ (Mac only), Internet \\
& Explorer ${ }^{\circledR} 11$ (Windows only), Edge 15 (Windows only) \\
& 4. & Mobile: Chrome ${ }^{\mathrm{TM}}$ 57, Firefox ${ }^{\circledR}$ Android 60 and iOS 20, Safari ${ }^{\circledR}$ iOS 10 \\
\hline
\end{tabular}

Table 1. Features of FCC

\section{Results Analysis:}

The result of the comparative analysis is tabulated under the following table 2 and divided into 6 sections according to some nature of the specific features. (FreeConferenceCall, n.d.-a) (GoToMeeting, n.d.) (Zoom, 2018) (Join.me, n.d.)

\begin{tabular}{|c|c|c|c|c|}
\hline Feature/Function & FCC & GTM & Zoom & Join.me \\
\hline \multicolumn{5}{|l|}{ A. Services } \\
\hline Audio conferencing & $\begin{array}{l}\text { 1,000 FREE } \\
\text { Participants } \\
\text { VoIP: included } \\
\text { Toll: included }\end{array}$ & $\begin{array}{l}50 \text { free participants } \\
\text { (14-day trial) } \\
\text { VoIP: included } \\
\text { Toll: included }\end{array}$ & $\begin{array}{c}50 \text { free participants } \\
\text { (14-day trial) }\end{array}$ & $\begin{array}{l}50 \text { free participants } \\
\text { (14-day trial) }\end{array}$ \\
\hline Video conferencing & $\begin{array}{l}\text { 1,000 FREE } \\
\text { Participants }\end{array}$ & $\begin{array}{l}50 \text { free participants } \\
\text { (14-day trial) }\end{array}$ & 100 free participants & $\begin{array}{l}10 \text { free participants } \\
\text { (14-day trial) }\end{array}$ \\
\hline Screen sharing & $\begin{array}{l}\text { 1,000 FREE } \\
\text { Participants }\end{array}$ & $\begin{array}{l}50 \text { free participants } \\
\text { (14-day trial) }\end{array}$ & 100 free participants & $\begin{array}{l}10 \text { free participants } \\
\text { (14-day trial) }\end{array}$ \\
\hline Time restrictions & 6 Hours & $\begin{array}{l}\text { Unlimited (14-day } \\
\text { trial) }\end{array}$ & 40 minutes & $\begin{array}{l}\text { Unlimited (14-day } \\
\text { trial) }\end{array}$ \\
\hline \multicolumn{5}{|c|}{ B. Audio Conferencing Features } \\
\hline International dial-in numbers & Free & $\$$ & $\$$ & $\$$ \\
\hline Web controls & Free & $\$$ & Free & $\$$ \\
\hline Breakout rooms & Free & $\mathrm{x}$ & Free & $\$$ \\
\hline Radio streaming & Free & $\mathrm{x}$ & $\mathrm{x}$ & $\mathrm{x}$ \\
\hline
\end{tabular}




\begin{tabular}{|c|c|c|c|c|}
\hline \multicolumn{5}{|l|}{ C. Video Conferencing Features } \\
\hline Multi-video feed & Free & $\$$ & $\mathrm{x}$ & $\$$ \\
\hline Active speaker technology & Free & $\mathrm{x}$ & $\$$ & $\mathrm{x}$ \\
\hline Join as view-only & Free & $\mathrm{x}$ & $\$$ & $\mathrm{x}$ \\
\hline Join by telephone & Free & $\$$ & $\$$ & $\$$ \\
\hline \multicolumn{5}{|l|}{ D. Screen Sharing Features } \\
\hline Switch presenter & Free & $\$$ & Free & $\$$ \\
\hline Remote control & Free & $\$$ & Free & $\$$ \\
\hline Whiteboarding & Free & $\$$ & Free & $\$$ \\
\hline \multicolumn{5}{|l|}{ E. Recording } \\
\hline $\begin{array}{l}\text { Audio, video and screen sharing } \\
\text { recording }\end{array}$ & Free & $\$$ & Free & $\$$ \\
\hline Create presentations & Free & $\mathrm{x}$ & $\$$ & $\mathrm{x}$ \\
\hline $\begin{array}{l}\text { Easy download, playback and } \\
\text { share }\end{array}$ & Free & $\$$ & $\$$ & $\$$ \\
\hline Broadcaster & Free & $\mathrm{x}$ & $\$$ & $\mathrm{x}$ \\
\hline Library of recorded files & Free & $\mathrm{x}$ & $\$$ & $\mathrm{x}$ \\
\hline Keywords & Free & $\mathrm{x}$ & $\mathrm{x}$ & $\mathrm{x}$ \\
\hline Automatic transcriptions & Free & $\mathrm{x}$ & $\mathrm{x}$ & $\mathrm{x}$ \\
\hline Storage & $1 \mathrm{~GB}$ Free & $\$$ & $\$$ & $\$$ \\
\hline \multicolumn{5}{|l|}{ F. Additional features } \\
\hline Site customization & Free & $\$$ & $\$$ & $\$$ \\
\hline File upload & Free & $\$$ & $\$$ & $\$$ \\
\hline Security & Free & $\$$ & Free & $\$$ \\
\hline Chat & Free & $\$$ & Free & $\$$ \\
\hline Q\&A & Free & $\$$ & $\$$ & $\$$ \\
\hline Mobile access & Free & $\$$ & $\$$ & $\$$ \\
\hline $\begin{array}{l}\text { No participant downloads (Web } \\
\text { Viewer) }\end{array}$ & Free & $\$$ & $\$$ & $\$$ \\
\hline
\end{tabular}




\begin{tabular}{|l|c|c|c|c|}
\hline 24/7 Customer Care & Free & Free & $\$$ & $\$$ \\
\hline \multicolumn{4}{|c|}{ *In Table 2, "\$" denotes paid services and " $\mathrm{x}$ " denotes services not available for that particular feature. }
\end{tabular}

Table 2. Comparative Study

Unavailability advertisements, quality issues, hidden fees, sales pitches, contracts, purchase requirement, privacy issues, restrictions and paid surprises; the FCC offers a truly free service and not a free trial for a certain duration. Accounts created on FCC never expire and one account can be used for an unlimited number of classes. FCC provides Call Detail Report (CDR) after every class and web conferencing via the email of the educator and which is very useful to analyze how students progress in the class and automatically marks the attendance. The report includes participant information such as time spent on each call and other meeting details. In a single conference call, FCC can accommodate a maximum of 1,000 participants. It also offers paid large meeting services allowing up to 5,000 participants. An event duration has the limit of six hours with an unlimited number of calls allowed. It has the feature of canceling static or echo on a conference call. FCC provides the benefit of collaborative video and screen sharing and increases productivity.

In an FCC virtual session (FreeConferenceCall, n.d.-b),

- hosts can access call controls on FCC, see the call list, display video and share computer screens, documents, web links or presentations.

- hosts can mute an individual participant using the Web Controls panel located on the Meeting Wall or the Meeting Dashboard by selecting a participant from the Attendee List and click Mute.

- hosts can click Chat on the Meeting Dashboard to message the whole group or private message an individual participant.

FCC is compatible with wide variety of devices and platforms for online webinars including PCs, Macs ${ }^{\circledR}$, Chromebooks ${ }^{\mathrm{TM}}$, iOS and Android ${ }^{\mathrm{TM}}$ phones and tablets. FCC also provides the facility of Remote desktop access with following steps (FreeConferenceCall, n.d.-c):

- First, Installed the FCC desktop application.

- Log in should be done with account email and password after click Host button.

- To grant remote control, under Attendee List, hover over the participant's name and click Down Arrow.

- Click Remote Control, then Allow keyboard and mouse.

- Choose Yes to confirm or No to cancel.

\section{Findings and Suggestions:}

i. The findings of the study recommends that FCC can be used by the HEIs and HRDs for conducting online classes, FDPs, RCs, OCs and STPs effectively, conveniently and securely with high affordability.

ii. FCC provides Desktop app, web app as-well-as mobile app making a wider choice available for the host and the participants. 
iii. FCC is available on multiple OS platform including $\operatorname{macOS} \AA$, Windows and Linux.

iv. As a mobile app, FCC is available for free download as Android an iOS platforms.

v. FCC integrates with Google and Outlook Calendar through free download extension/Plug-in.

vi. "FreeConferenceCall.com Scheduler" Chrome Extension for Google Calendar ${ }^{\mathrm{TM}}$ provides a quick and easy way to schedule a virtual meet by creating an event, then clicking Add and Save. Users are able to join the meeting or host one from the Google Calendar event by clicking Join or Host respectively.

\section{Discussion:}

The base of this paper depends on the primary requirements of internet facility and knowledge of access in the web i.e. Digital Literacy. The term 'digital literacy' is used to describe the ability to harness the potential of digital tools (IFLA, 2017). In the process of transmission, the learning process from conventional to digital equal access of web is also necessary because as of the print material web also demands money for getting access and which creates a void between the research and researcher, information and seeker, educator and learner, query and the solutions. In the last decades, efforts to bridge the digital divide have focused on access, i.e. ensuring that everyone is connected to the internet. Inequalities remain though: over half the world population still doesn't have internet access, mostly underprivileged individuals in both developing countries and industrialised countries. The last few years, in particular with the emergence of e-government initiatives, made it clear that accessibility is as important an issue (Lachal \& Peich, 2018). The 5A's of access gives a theoretical framework of this bridging of the digital divide. Which include,

\begin{tabular}{|c|c|c|}
\hline SN & he A5s & FCC \\
\hline A1 & Availability & $\begin{array}{l}\text { Whether services are available in the first place. } \\
\text { For FCC availability, the FCC server health was tested using https://uptime.com. The } \\
\text { result, as displayed in fig. 1, depicts high web server availability. }\end{array}$ \\
\hline A2 & Adequacy & $\begin{array}{l}\text { Whether there is an adequate and continued supply of available services. The } \\
\text { comparison table } 2 \text {, depicts the adequacy of FCC owing to its richness of features even } \\
\text { in its free version with the capability of accommodating } 1000 \text { users and } 6 \text { hours of } \\
\text { generous meeting duration. }\end{array}$ \\
\hline A3 & Accessibility & $\begin{array}{l}\text { Whether the services are effectively available for utilization. FCC is available for all } \\
\text { the popular OSS including macOS } \AA \text {, Windows and Linux. For the mobile devices, } \\
\text { FCC has its presence for Android }{ }^{\mathrm{TM}}, \mathrm{iPhone} \AA \text {, } \mathrm{iPad} \AA \text { or } \mathrm{iPad} \text { Pro }{ }^{\circledR} \text {. It supports wide } \\
\text { Integrations with Google Calendar, Microsoft Outlook Calendar, Slack, Dropbox and } \\
\text { Evernote. Thus is can be inferred that FCC is Accessible. Availability of free version } \\
\text { also endorses this point. }\end{array}$ \\
\hline A4 & Affordability & $\begin{array}{l}\text { Affordability refers to removal of financing burden for availing any important service } \\
\text { or solution and the produc has its reach to the masses including those lacking higher } \\
\text { purchasing power. FCC fulfils this criteria as it allows its free usage without financial } \\
\text { obligation. }\end{array}$ \\
\hline A5 & Appropriateness & $\begin{array}{l}\text { Service/product available must be relevant and useful to the user as well is } \\
\text { organizational needs and it should lead to meaningful and satisfactory outcomes. Here } \\
\text { also, FCC qualifies owing to the provision of all the major requirements of a webinar }\end{array}$ \\
\hline
\end{tabular}


Table 3. FCC and 5 A's of Access

(4) Web Server

\begin{tabular}{|c|c|c|c|c|c|}
\hline & & TYPE & TEST & RESULT & \\
\hline$\nabla$ & $\checkmark$ & HTTPS & $\begin{array}{l}\text { Web Server } \\
\text { HTTPS }\end{array}$ & HTTP OK: HTTP/1.1 200 OK - 8191 bytes in 0.806 second response time & (- More Info \\
\hline$\nabla$ & $\checkmark$ & $\begin{array}{l}\text { SSL } \\
\text { Certificate }\end{array}$ & $\begin{array}{l}\text { SSL Certificate } \\
\text { Expiry }\end{array}$ & $\begin{array}{l}\text { SSL_CERT OK - x509 certificate 'www.freeconferencecall.com' from 'Go Daddy Secure Certificate Authority - G2' } \\
\text { valid until Nov } 22 \text { 22:34:00 } 2020 \text { GMT (expires in } 122 \text { days) }\end{array}$ & (3) More Info \\
\hline ఐ & $\checkmark$ & HTTP & $\begin{array}{l}\text { Web Server } \\
\text { HTTP }\end{array}$ & HTTP OK: HTTP/1.1 200 OK - 8191 bytes in 1.610 second response time & (3) More Infc \\
\hline ఐ & $\checkmark$ & $\begin{array}{l}\text { Ping } \\
\text { (ICMP) }\end{array}$ & $\begin{array}{l}\text { Ping (ICMP) - } \\
12.7192 .60\end{array}$ & PING OK - Packet loss $=0 \%$, RTA $=66.34 \mathrm{~ms}$ & (3) More Infe \\
\hline
\end{tabular}

Fig 1. FCC Domain Health Check on Uptime

(Tool: uptime.com/)

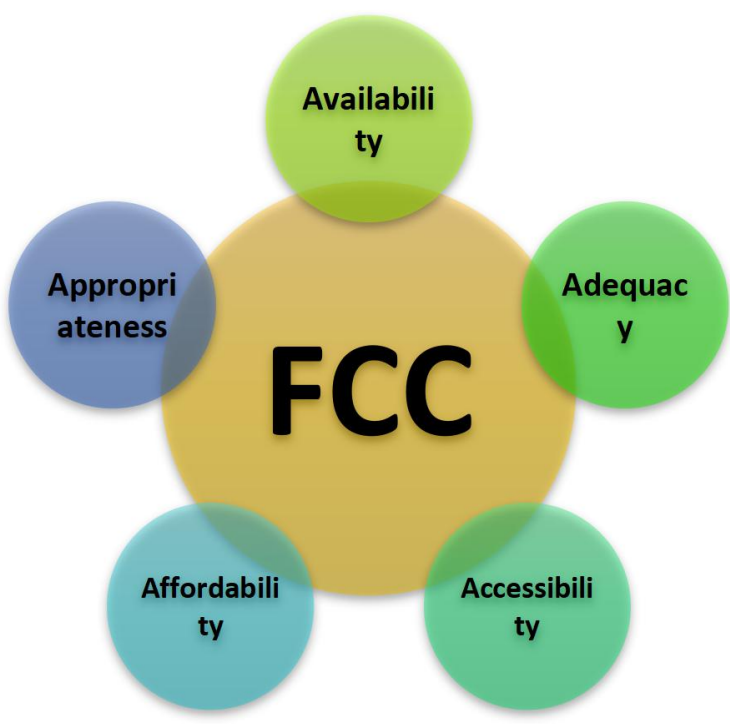

Fig 2. FCC and 5A's of Accessibility 
The analysis of the paper suggests that web-conferencing tool FCC satisfies all the 5A's of access and prove its impacts not only on academic and professional achievement, cognitive development but also on social inclusion, empowerment and citizenship, advocating for the inclusion of a digital literacy capacity-building strategy for all in e-governments initiatives.

\section{Discussion:}

21st Century teaching and learning strategies related to the various methods used include the use of appropriate tools with the latest technological developments to help students to understand clearly about the content of the subject (Ovcharuk et al., 2020). But still people resist change without understanding the need and importance of it and when a situation arises all should adapt to change willingly and unwillingly. This was the situation which occurred to teaching fraternity too. Indian higher education institution has used various pedagogy for innovation, development, and engagement of students. Many faculties have resisted the change when they had been asked to take virtual classes for students. And a couple of training was provided by the management of the institutions hence faculty will not face any difficulties on the same. As everything exists in the mindset, the mindset has to be changed towards the adoption and adaption of virtual classroom and adopt technology for the betterment of students (Shenoy, Mahendher, \& Vijay, 2020).

\section{Conclusion:}

FreeConferenceCall.com is an intuitive and agile collaboration tool packed with features to allow hosts to conduct audio conference calls and online meetings. All accounts include HD audio, screen sharing and video conferencing for up to 1,000 participants at no cost. During a conference, use phone keypad commands or web controls to record, lock, mute and more. Each account has a customizable meeting wall to showcase important information and resources for a meeting. At the end of a meeting, access History \& Recordings from your online account for playback, download, sharing and comprehensive reporting. Screen sharing and video conferencing are common features in an online classroom. With the use of video conferencing and webcam, educators and learners can share screens, documents, slides, spreadsheets, etc and meet face to face similar as in the physical classroom. FCC is such a web conferencing tool which offers HD audio, screen sharing and video conferencing for up to 1,000 participants to simplifies conduct of online events and classes with complete freedom to connect in less time with high-quality, secure and free collaboration. FCC is a tool which conforms 5A's of access i.e. Availability, Adequacy, Accessibility, Affordability and Appropriateness; that bridges the digital divide by ensuring the equal access of web for all. In conclude we can say that, the paper illustrates thoroughly how an web conferencing tool help us to fight against the transformation from conventional to digital way of learning in situation of such disaster like the recent outbreak of COVID-19 and suggest that educators and learners must be ready to adopt new changes and requirement of the present situation. 


\section{References:}

Alolod, G. ., Gardiner, H., Agu, C., Turner, J. ., Kelly, P. ., Siminoff, L. ., Gordon, E. ., Norden, R., Daly, T. ., Benitez, A., Hernandez, I., Guinansaca, N., Winther, L. ., Bergeron, C. ., Montalvo, A., \& Gonzalez, T. (2020). A culturally targeted eLearning module on organ donation (promotoras de Donación): Design and development. Journal of Medical Internet Research, 22, Article 1. https://doi.org/10.2196/15793

Ansong-Gyimah, K. (2020). Students' perceptions and continuous intention to use elearning systems: The case of google classroom. International Journal of Emerging Technologies in Learning, 15, 236-244. https://doi.org/10.3991/IJET.V15I11.12683

Anthonysamy, L., Choo, K. ., \& Hin, H. . (2020). Impact of cognitive and metacognitive strategies on learning performance in digital learning: What's working and what's not in the age of brilliant technology. Journal of Physics: Conference Series, 1529, Article 5. https://doi.org/10.1088/1742-6596/1529/5/052019

Bauwens, R., Muylaert, J., Clarysse, E., Audenaert, M., \& Decramer, A. (2020). Teachers' acceptance and use of digital learning environments after hours: Implications for work-life balance and the role of integration preference. Computers in Human Behavior, 112. https://doi.org/10.1016/j.chb.2020.106479

Blake, H., Bermingham, F., Johnson, G., \& Tabner, A. (2020). Mitigating the psychological impact of covid-19 on healthcare workers: A digital learning package. International Journal of Environmental Research and Public Health, 17, Article 9. https://doi.org/10.3390/ijerph17092997

Cotwright, C. ., Bradley, H., Celestin, N., Lee, J. ., Hall, J. ., Stotz, S., \& Birch, L. (2020). Determining eLearning preferences to inform beverage policy training for early care and education teachers. Journal of Nutrition Education and Behavior. https://doi.org/10.1016/j.jneb.2020.02.020

FreeConferenceCall. (n.d.-a). Features | FreeConferenceCall.com. Retrieved July 3, 2020, from https://www.freeconferencecall.com/global/in/features

FreeConferenceCall. (n.d.-b). Host Instructions | FreeConferenceCall.com. Retrieved July 1, 2020, from https://www.freeconferencecall.com/host-instructions

FreeConferenceCall. (n.d.-c). Support | FreeConferenceCall.com. Retrieved July 2, 2020, from https://www.freeconferencecall.com/global/support

Gegenfurtner, A., Zitt, A., \& Ebner, C. (2020). Evaluating webinar-based training: a mixed methods study of trainee reactions toward digital web conferencing. International Journal of Training and Development, 24, 5-21. https://doi.org/10.1111/ijtd.12167 
González-Sanmamed, M., Estévez, I., Souto-Seijo, A., \& Muñoz-Carril, P.-C. (2020). Digital learning ecologies and professional development of university professors. Comunicar, 28, 9-18. https://doi.org/10.3916/C62-2020-01

GoToMeeting. (n.d.). Online Meeting Software, Video Conferencing \& Web Conferencing | GoToMeeting. Retrieved July 3, 2020, from https://www.gotomeeting.com/en-in

Grabowski, E., Alten, F., Termühlen, J., Heiduschka, P., Brücher, V., Eter, N., \& Clemens, C. . (2020). Analysis of the importance of e-learning in ophthalmology and evaluation of an e-learning app [Analyse des Stellenwertes von „eLearning“ in der Augenheilkunde und Evaluierung einer „eLearning-App“]. Ophthalmologe. https://doi.org/10.1007/s00347-020-01100-x

Hill, S. ., \& Johnson, P. W. . (2020). Elearning for cancer immunotherapy. Ecancermedicalscience, 14. https://doi.org/10.3332/ECANCER.2020.ED94

IFLA. (2017, August 18). IFLA -- IFLA Statement on Digital Literacy (18 August 2017). Retrieved July 5, 2020, from https://www.ifla.org/publications/node/11586

Ivanova, M. (2020). eLearning informatics: From automation of educational activities to intelligent solutions building. Informatics in Education, 19, 257-282. https://doi.org/10.15388/INFEDU.2020.13

Join.me. (n.d.). Audio \& Video Conferencing Features | join.me. Retrieved July 3, 2020, from https://www.join.me/en/features

Kummanee, J., Nilsook, P., \& Wannapiroon, P. (2020). Digital learning ecosystem involving steam gamification for a vocational innovator. International Journal of Information and Education Technology, 10, 533-539. https://doi.org/10.18178/ijiet.2020.10.7.1420

Kurdi, B. ., Alshurideh, M., Salloum, S. ., Obeidat, Z. ., \& Al-dweeri, R. . (2020). An empirical investigation into examination of factors influencing university students' behavior towards elearning acceptance using SEM approach. International Journal of Interactive Mobile Technologies, 14, 19-41. https://doi.org/10.3991/ijim.v14i02.11115

Lachal, J., \& Peich, M.-C. (2018, August 29). Bridging the digital divide: a prerequisite for global egovernment. IFLA WLIC 2018 - Kuala Lumpur, Malaysia - Transform Libraries, Transform Societies in Session 233 Government Information and Official Publications. Retrieved from http://library.ifla.org/2210/1/233-lachal-fr.pdf

Mahmood, A. ., Lah, H. ., Ghani, R. ., Rahman, M. N. ., Sulaiman, I., \& Mustafa, W. . (2020). Design and user satisfaction digital learning through kelana peribahasa. Journal of Physics: Conference Series, 1529, Article 4. https://doi.org/10.1088/1742-6596/1529/4/042043 
Mishra, K., Bukavina, L., Arora, H., \& Campbell, S. . (2020). Quantitative assessment of a case based digital learning curriculum for testicular cancer. Urology, 135, 28-31. https://doi.org/10.1016/j.urology.2019.10.002

Muniasamy, A., \& Alasiry, A. (2020). Deep learning: The impact on future eLearning. International Journal of Emerging Technologies in Learning, 15, 188-199. https://doi.org/10.3991/IJET.V15I01.11435

Murphy, M. P. . (2020). COVID-19 and emergency eLearning: Consequences of the securitization of higher education for post-pandemic pedagogy. Contemporary Security Policy, 41, 492-505. https://doi.org/10.1080/13523260.2020.1761749

Ovcharuk, O., Ivaniuk, I., Soroko, N., Gritsenchuk, O., \& Kravchyna, O. (2020). The use of digital learning tools in the teachers' professional activities to ensure sustainable development and democratization of education in European countries. E3S Web of Conferences, 166. https://doi.org/10.1051/e3sconf/202016610019

Patient Access Partnership. (n.d.). 5A's of Access. Retrieved July 4, 2020, from https://www.eupatientaccess.eu/page.php?i_id=19

Shenoy, V., Mahendher, S., \& Vijay, N. (2020). COVID 19 Lockdown Technology Adaption, Teaching, Learning, Students Engagement and Faculty Experience. Mukt Shabd Journal, 9(4), 698-702. Retrieved from https://www.researchgate.net/publication/340609688

University Grants Commission. (2018, July 4). Notification | The Gazette of India: Extraordinary. Retrieved from https://www.ugc.ac.in/pdfnews/7553683_Online-Courses-or-ProgrammesRegulations_2018.pdf

University Grants Commission. (2020, January 17). Notification | The Gazette of India: Extraordinary. Retrieved from https://www.ugc.ac.in/pdfnews/6758108_Online-Amendment-Regulation.pdf

Uptime. (n.d.). Website Uptime Monitoring Service | Uptime.com. Retrieved July 4, 2020, from https://uptime.com/

Zoom. (2018). Video Conferencing, Web Conferencing, Webinars, Screen Sharing. Retrieved July 3, 2020, from https://zoom.us/ 